\title{
Use of Fuzzy Set Theory in Environmental Engineering Applications: A Review
}

\author{
Arif Khan \\ Principal, NCET, Kalmeshwar, Nagpur
}

\begin{abstract}
Methods of solving the identified environmental problems, considering mathematical rigorous alternative assessment of environmental component process using fuzzy logic and approximate reasoning, are described by various researchers. To illustrate how such a computational intelligence approach would work in performing an assessment, various artificial techniques have been described. Fuzzy system technique for analysis of environmental components differentiates the approach from those techniques used in the past. It takes advantage of advanced computational intelligence techniques such as fuzzy sets and logic, for quantifying and manipulating in a mathematically rigorous way, subjective, inherently uncertain or imprecise values and concepts. This paper put forth the use of fuzzy sets in field of environmental engineering.
\end{abstract}

Keywords: Fuzzy set theory, environmental components, Artificial intelligence, and environmental variables.

\section{Introduction}

The need for more appropriated techniques to manage the importance of environmental variables, the interpretation of an acceptable range for each parameter, and the method used to integrate dissimilar parameters involved in the evaluation process is clearly recognized. In this sense, some alternative methodologies have emerged from artificial intelligence. These methodologies, mainly fuzzy logic and fuzzy sets, are being tested with real environmental problems. The final aim is to reduce the uncertainty and imprecision in criteria employed in decision-making tools. [6, 10, 23]

It is proposed by many researchers to use the methods based on fuzzy sets theory to handle the uncertainty involved in analysis of Water, Air, Land, Biological and socio-economic concepts. Keeping the importance of uncertainty handling in the environmental quality assessment and versatility of the fuzzy set theory in the decision making in the imprecise environment', continuous attempts are being made to describe the environmental quality by considering the fuzzy set theory.

\section{Fuzzy Set Theory in Environmental Engineering Applications}

Bhupinder Singh et al (2008) applied fuzzy rule based optimization model for twenty groundwater samples from Sohna town of Gurgaon district of Southern Haryana, India. These samples were analysed for 15 different physico-chemical parameters, out of them nine important parameters were used for the quality assessment using fuzzy synthetic evaluation approach. They concluded that all the water samples are in acceptable category whose certainty level ranges from 44 to $100 \%$. Water from these sources can be used for the drinking purposes if alternate water source is not available without any health concern on the basis of physicochemical characteristics.

Aurelio Azevedo Barreto- Neto and Carlos Roberto de Souza filho (2008) suggested the Fuzzy Soil Conservation Service Curve Number (SCSCN) model used as a tool for predicting runoff and, consequently, soil erosion and quality of water in watersheds. The program developed here can produce fuzzy boundaries with different widths and can be used with numerous membership functions by simple changes in program script

Yilmaz Icaga (2007) used Fuzzy logic with an index model for quality evaluation of surface water quality classification using fuzzy logic. In the method, traditional quality classes are transformed into continuous form and then the concentration values of the different quality parameters $(\mathrm{pH}, \mathrm{DO}$, $\mathrm{Cl}, \mathrm{SO}_{4}, \mathrm{NH}_{3}, \mathrm{NO}_{2}, \mathrm{NO}_{3}, \mathrm{TDS}$, Color, Na) are summed using fuzzy rules, finally, defuzzyfication of this summed values develops the index. He concluded that more accurate information may be obtained using continuous from which is obtained by Fuzzy logic.

Based on the Fuzziness and imprecision of water system, the LI Ru-zhong (2007) used the fuzzy arithmetic to simulate the fuzzy and imprecise relations in river quality modeling. By defining the parameters of water quality model as symmetrical triangular fuzzy numbers, a two-dimensional fuzzy water quality model for sudden pollutant discharge is established. From the fuzzy model, the pollutant 
concentrations, corresponding to the specified level of $\alpha$, can be obtained by means of the $\alpha$-cut technique and arithmetic operations of triangular fuzzy numbers. Study results reveal that it is feasible in theory and reliable on calculation applying triangular fuzzy numbers to the simulation of river water quality.

Ajit Prabat Singh et al (2007) developed Interactive Fuzzy Multi-objective linear Programming (IFMOLP) model for water quality management in a river basin and will first evaluate Dissolved Oxygen (DO) concentrations or DO deficits at a point in different reaches depending on the overall Biochemical Oxygen Demand (BOD) concentration present in the respective drain. They found that the model provides flexibility for all objective of the decision maker to specify their aspirations independently. By interacting with the $\mathrm{DM}$, the different aspiration levels for improving water quality and minimizing treatment costs are specified and the compromise solutions of the treatment levels have been achieved. Sudhir Dahiya et al (2007) reported that the application of fuzzy set theory for decision-making in the assessment of physico-chemical quality of groundwater for drinking purposes. Fuzzy synthetic evaluation model gives the certainty levels for the acceptability of the water based on the prescribed limit of various regulatory bodies quality class and perception of the experts from the field of drinking water quality. Application of fuzzy rule based optimization model is illustrated with 42 groundwater samples collected from the 15 villages of Ateli block of southern Haryana, India. Finally they concluded that about $64 \%$ water sources were either in "desirable" or "acceptable" category for drinking purposes. William Ocampo-Duque et al (2006) collected data from the Ebro River (Spain) by two different environmental protection agencies and Proposed a methodology based on fuzzy inference systems (FIS) to assess water quality. They developed a water quality index calculated with fuzzy reasoning .There findings, managed within a geographic information system; clearly agree with official reports and expert opinions about the pollution problems in the studied area. Therefore, this methodology emerges as a suitable and alternative tool to be used in developing effective water management plans.

Ho Wen Chen et al (2005) provides a technical analysis using the fuzzy contingent valuation method (FCVW) to value in-stream water quality improvements in terms of three fuzzy resources from aesthetic to recreational, and to ecological aspects. The information summarized from the regression analysis clearly shows that the total benefits of the instream water quality improvements are proportional to the number of resident living in that area that are influenced by the instream water quality.

W. C. Ip et al (2005) applied a data-mining type approach to evaluate the water quality of Hang Jiang River based on water quality measurements collected at selected stations during various periods. In this they have reduced the thirteen water quality attributes to 4or 5 important ones which determine the overall water quality for the segments and periods under consideration. These attributes are important in the sense that they determine the DM rules which in turn give WQ measures. An important attribute does not necessarily imply that the higher level of it will cause water to be more polluted, but it is important to account for the variations in water quality. Dr. Arvind K. Nema and Rajneesh Rai studied Groundwater classification scheme based on fuzzy logic based approach using Groundwater quality data obtained from seven places including an industrial area in the city of Kolkatta and the classification has been carried out using five parameters viz. Temperature, BOD, pH, Nitrates and Faecal Coliforms. A water sample can be classified as good, medium or bad but with different degrees of certainty. Finally concluded that field data provide many uncertainties. Hence a new approach using fuzzy logic- a soft computing technique has been used in this study. Chih-Sheng Lee and Shui-Ping Chang (2005) demonstrated the capability of the fuzzy interactive multi-objective optimization approach by using three major economic and environmental factors: river water quality, assimilative capacity, and treatment cost of waste water, the case study indicates that, For an economic and environmental balance in a river system, for the constraint of the same equitable removal levels, a higher water quality level may be achieved at the monitoring stations. It also work suitably in water quality management in a river basin by the trade-off procedures. Ni-Bin Chang et al (2001) Conducted a comparative study for the Tseng-Wen River system in Taiwan using three fuzzy synthetic evaluation techniques to assess water quality conditions in comparison to the outputs generated by conventional procedures such as the Water Quality Index (WQI).There findings clearly indicate that the techniques may successfully harmonise inherent discrepancies and interpret complex conditions. Fuzzy synthetic evaluation approach also useful for verifying water quality conditions for the Total Maximum Daily Load (TMDL) program and be helpful for constructing an effective water quality management strategy. Hercules Mpimpas et al (2001) Conducted a field study of pollution using water pollution model in the Gulf of Thermaikos, in this the physico-chemical coefficients and the loads of pollution sources are expressed in the form of triangular fuzzy numbers. A two-dimentional finite 
element algoritm, combined with fuzzy logic analysis, is used for the solution of the advectiondispersion equation for ten different water quality variables. The technique yields the most confident value of each quality variable, and is very efficient for the determination of the extreme values of these qualities.

Catherine Freissinet et al (1998) introduced various types of imprecisions either by subjective or state-of-art estimates of coefficients, or through measurement error, and on their evaluation by fuzzy set and fuzzy logic theory and finally concluded that the fuzzy logic - based approach is a complementary method to deterministic physically-based modeling, which adds an imprecision range and a degree of confidence to the mean value of the numerical result. It appears very promising for risk analysis studies.

Nobuya Saruwatarim and Atsushi Yomota (1995) conducted a study on forecasting system of irrigation water requirements which can support the operational work of administrators regarding water supply and water distribution in the irrigation schemes. They confirmed the availability of the system by testing in the field and suggested the possibility of applying the forecasting system to basin water management, also concluded that systematization disregarding human relation is meaningless and is never useful because Agricultural production is originally based on human activities.

Alex. B. McBratney and Inakwu O. A. Odeh (1997) suggested Fuzzy set theory, Fuzzy logic applications in soil science which includes Soil numerical classification and mapping, Land evaluation, Modelling and simulation of soil physical processes, Fuzzy variogram and kriging of soil variables, Grey-scale digital image analysis, Fuzzy measures of imprecisely defined soil phenomena, Soil quality indices and concluded that fuzzy set theory has great potential in soil science.

Guleda Onkal-Engin et al (2004) provides a methodology for urban air quality using fuzzy synthetic evaluation techniques in European part of Istanbul. Air pollutants data such as Sulphur Dioxide $\left(\mathrm{SO}_{2}\right)$, Carbon Monoxide $(\mathrm{CO})$, Nitrogen Dioxide $\left(\mathrm{NO}_{2}\right)$, Ozone $\left(\mathrm{O}_{3}\right)$, and total suspended particulate matter (PM) collected at five different air quality monitoring stations located in western part of Istanbul was used in this evaluation. The results obtained were compared to those applied to EPA air quality index and concluded that these techniques are relatively suitable for urban air quality management.

Aluclu et al (2008) describes noise-human response and developed fuzzy logic model by comprehensive field studies on noise measurements (including atmospheric parameters) and control measures. They compared results of the model with various statistics (correlation coefficients, max-min, standard deviation, average and coefficient of skew ness) and error modes (root mean square error and relative error) and found that the correlation coefficients were significantly high, error modes were quite low and the other statistics were very close to the data from this they concluded that the model can be used for noise control in any workplace and helpful to the designer in planning stage of a workplace.

Environmental Impact Assessment (EIA) is an efficient method for preserving natural resources and protecting the environment. Therefore, most developed countries have introduced EIA into their regulations, and the consequent approval of all projects (Council of European Union, 1996; EPA, 2007). This assessment involves forecasting and estimating all the environmental impacts inherent in the execution of the project.

Today there are different methodologies to carry out EIAs. Although most were designed to assess the Environmental Impacts (EI) of specific projects, some more universally applicable methods have also been developed (Conesa, 1997; Erikstad et al., 2008). The most advanced EIA-methods require some specific parameters and diverse variables to be measured in order to estimate the values of the impact indicators, which have to be converted - in turn - to a sole environmental quality scale in order to obtain a global assessment of the different impacts. However, frequently it is not possible to describe many of the environmental impact properties by means of objective indicators (e.g. landscape quality, lifestyle quality, social acceptance,) and, moreover, the estimation of the values of these indicators is often affected by a high degree of inaccuracy and uncertainty. Similarly, the conversion of indicator values to a sole environmental quality scale involves a diagnosis, which is often not free from subjectivity, due to the different criteria and value judgments of householders and so, subjectivity and uncertainty are implicit to some extent or other in EIAs. Consequently, to assess the impacts we may resort to expert criteria, available information on the EI of similar projects, sensitivity of the affected population, environmental regulations, etc. Systematic treatment of this information, which is generally inaccurate and - in many cases — based on non quantitative and linguistic variables, requires the use of a suitable methodology and so, fuzzy logic - by means of fuzzy arithmetic and approximate reasoning methods - maybe a fitting way to develop new EIA-approaches. [23; 28]

Fuzzy logic has been successfully applied in the environmental field. A number of representative examples of such applications can be quoted in the last two decades, such as surface water and groundwater remediation [36; 25], soil amendments [8], air pollution management [15], and diverse air, water and terrestrial ecosystem environmental 
studies. Fuzzy logic has also been used in other environmental issues, such as ecological impact classification [35], design of environmental indicators [35;38], industrial green engineering [12] and in the assessment of environmental integrated models [24], sustainable development [4], risks [20] and life cycle [21]. However, there are few studies published about environmental impact assessment by fuzzy logic. Anile et al. (1995) propose a method to assess Leopold's matrix by fuzzy arithmetic. Parashar et al. (1997) utilize fuzzy cross-impact simulation as an environmental assessment method. Enea and Salemi (2001) describe a procedure in which the environmental parameters are defined by fuzzy numbers and propose suitable operators to estimate environmental impact in fuzzy terms. Peche (2006) has lately published a study describing a qualitative assessment of environmental impact method - the generalized modus ponens-method, by using the fuzzy inference method to estimate each impact. It is as well to point out that most published works related to environmental assessments by means of fuzzy logic are founded on a knowledge base formed by a set of fuzzy rules and on the fuzzyfication of the input parameters so that they can be applied to the inference system. Some representative examples of this are the risk assessment of groundwater pollution [37], the quality assessment of groundwater [6] and river water [27] and the decision-making method to assess environmental impacts [13]. These all the methods mentioned above, applied fuzzy set theory either to existing methodology of EIA or to a part of environmental issues. None of the method applied fuzzy set theory to deal with all the components of environment in a nutshell

\section{Conclusion}

Fuzzy logic can be considered a priori a useful tool to assess different environmental issues or the total impact associated with the execution of activities and projects. This is especially applicable when quantitative information about environmental components is short, inaccurate, and uncertain and described in linguistic terms. Therefore, the objective of this study is to describe procedure based on fuzzy logic in order to carry out the analysis of environmental issues where uncertainty is involved, but, unlike the aforementioned procedures, this new approach formulates a different option of application of fuzzy logic to the environmental components.

\section{Bibliography}

[1] Ajit Pratap Singh et al, 2007, Water quality management of a stretch of river Yamuna: An interactive fuzzy multi-objective approach. · S. K. Ghosh · Pankaj Sharma,.Water Resour Management 21:515-532
[2] Alex. B. McBratney et al, 1997, Application of fuzzy sets in soil science: fuzzy logic, fuzzy measurements and fuzzy decisions, Cooperative Research Centre for Sustainable Cotton Production, Department of Agricultural Chemistry and Soil Science, The University of Sydney, Sydney, NSW 2006, Australia . Geoderma 77 (1997) 85113

[3] Aluclu et al (2008), A fuzzy logic-based model for noise control at industrial workplaces, Applied Ergonomics, Volume 39, Issue 3, may 2008.

[4] Andriantiatsaholiniaina LA, Kouikoglou VS, Phillis YA, 2004, Evaluating strategies for sustainable development: fuzzy logic reasoning and sensitivity analysis. Ecol Econ 2004; 48:149-72.

[5] Anile AM, Deodato S, Privitera G. 1995, Implementing fuzzy arithmetic. Fuzzy Sets Syst; 72:239-50. Astel A. Chemometrics based on fuzzy logic principles in environmental studies. Talanta 2007;72:112.

[6] Arif Khan, "Fuzzy Logic Approach to Quantify Water Pollution" International Journal of Engineering Science and Computing, IJESC, ISSN 2321 3361, IF 5.611, Volume 7, Issue No. 5, May 2017.

[7] Aurelio Azevedo Barreto- Neto and Carlos Roberto de Souza filho (2008), Application of fuzzy logic to the evaluation of runoff in a tropical watershed, Environmental Modelling \& Software, Volume 23 Issue 2, February, 2008

[8] Busscher W, Krueger E, Novak J, Kurtener D, 2007, Comparison of soil amendments to decrease high strength in SE USA coastal plain soils using fuzzy decision-making analysis. Int Agrophys 2007; 21:225-31.

[9] Catherine Freissinet et al (1998), A fuzzy logic-based approach to assess imprecisions of soil water contamination modeling, Soil and Tilage Research, Volume 47, Issues 1-2, June 1998. Pages 11-17

[10] Chang PT, Huang LC, Lin HJ. The fuzzy Delphi method via fuzzy statistics and membership function fitting and an application to the human resources. Fuzzy Sets Syst 2000; 112:511-20.

[11] Chih-Sheng Lee and Shui-Ping Chang (2005), Sustainable Watershed Management by Fuzzy game optimization, International Environmental Modelling and Software Society, Modelling for Environment's Sake, fifth Biennial Meeting, Ottawa, Canada.

[12] Chiou HK, Tzeng GH. Fuzzy multiplecriteria decision-making approach for 
Dahiya, S., B. Singh, S. Gaur, V.K. Garg and H.S. Kushwaha, 2007. Analysis of groundwater quality using fuzzy synthetic evaluation. J. Hazard. Mater., 147: 938-946. industrial green engineering. Environ Manag 2002; 30:816-30.

[13] De Siqueira and De Mello, 2006). A decision support method for environmental impact assessment using a fuzzy logic approach, Ecological Economics, 2006, vol. 58, issue 1, pages $170-181$

[14] Enea and Salemi (2001), fuzzy approach to the environmental impact evaluation, ecological Modelling, 135 (2001) 131-147

[15] Fisher B. Fuzzy environmental decisionmaking: applications to air pollution. Atmos Environ 2003;37:1865-77.

[16] González B, Adenso-Díaz B, GonzálezTorre PL. 2002, A fuzzy logic approach for the impact assessment in LCA. Resour Conserv Recycl 2002;37:61-9.

[17] Guledo Onkal-Engin et al, 2004, Assessment of urban air quality in Istanbul using fuzzy synthetic evaluation, Ibrahim Demir, Halil Hiz. Department of Environmental Engineering, Gebze Institute of technology, Gebze 41400, Kocaeli, Turkey. Atmospheric Environment 38 (2004) 3809-3815

[18] Hercules Mpimpas et al (2001), Modelling of water pollution in the Thermaikos Gulf with fuzzy parameters, Ecological Modelling, Volume 142, Issues 1-2, Pages 91-104.

[19] Ho-Wen Chen, 2005, Valuation of instream water quality improvement via fuzzy contingent valuation method, Stoch Environ Res Risk Assess (2005) 19: 158-171,

[20] $\mathrm{Li} \mathrm{J}$ et al 2007, An integrated fuzzystochastic modeling approach for risk assessment of groundwater contamination. $\mathbf{J}$ Environ Manag 2007;82:173-88.

[21] González B, Adenso-Díaz B, GonzálezTorre PL. 2002, A fuzzy logic approach for the impact assessment in LCA. Resour Conserv Recycl 2002;37:61-9.

[22] Guledo Onkal-Engin et al, 2004, Assessment of urban air quality in Istanbul using fuzzy synthetic evaluation, Ibrahim Demir, Halil Hiz. Department of Environmental Engineering, Gebze Institute of technology, Gebze 41400, Kocaeli, Turkey. Atmospheric Environment 38 (2004) 3809-3815

[23] McKone TE et al. Can fuzzy logic bring complex environmental problems into focus? Environ Sci Technol 2005; 39(2):42A-7A.
[24] Mackay DS, Robinson VB. 2000, A multiple criteria decision support system for testing integrated environmental models. Fuzzy Sets Syst 2000;113:53-67.

[25] Nasiri F, Huang G, Fuller N. Prioritizing groundwater remediation policies: a fuzzy compatibility analysis decision aid. $\mathbf{J}$ Environ Manag 2007;82:13-23.

[26] Ni-Bin Chang et al, G. Parvathinathan, Jeff B Breeden, 2001, Combining GIS with fuzzy multicriteria decision making for Landfill sitting in a fast growing urban region, Journal of environmental Management 87 (2008 139-153) (2001), G. $\mathrm{Pa}$

[27] Ocampo - Duque et al., 2006, Ph.D. thesis on the development of decision making system based on fuzzy model to assess water quality in river. Department of Chemical Engineering, University of Rovira I Virgili, Tarragona- 2008.

[28] Özesmi U, Özesmi SL. Ecological models based on people's knowledge: a multi-step fuzzy cognitive mapping approach. Ecol Model 2004;176:43-64.

[29] Parashar A, Paliwal R, Rambabu P. Utility of fuzzy cross-impact simulation in environmental assessment. Environ Impact Asses Rev 1997;17:427-47.

[30] Peche (2006), Environmental impact assessment by means of a procedure based on fuzzy logic: A practical application, Gest Ambient 2006;9:99-113.

[31] Peter Morris, Therivel Riki, 2001, Methods Of Environmental Impact Assessment, Taylor \& Francis, Mortimer House, 37-41 Mortimer Street, London.

[32] Peter Morris, Therivel Riki, 2001, Methods Of Environmental Impact Assessment, Taylor \& Francis, Mortimer House, 37-41 Mortimer Street, London.

[33] Rao, 1997, Environmental Impact Assessment, Mcgraw hills Publication, US.

[34] Rau and Wooten, 1980, Introduction to Environmental Impact Assessment, McGraw Hill Higher Education.

[35] Silvert, W. (2000). Fuzzy indices of environmental conditions. Ecological Modeling, 130:111-119.

[36] Tzionas P, Ioannidou IA, Paraskevopoulos S. A hierarchical fuzzy decision support system for the environmental rehabilitation of Lake Koronia. EnvironManag 2004;34:245-60.

[37] Uricchio VF, Giordano R, Lopez N. A fuzzy knowledge-based decision support system for groundwater pollution risk evaluation. J Environ Manag 2004;73:189-97. 
[38] Van Der Werf and Zimmer, 1998; An indicator of pesticide environmental impact based on a fuzzy expert system, Chemosphere 36, 2225-2249.

[39] W. C. Ip et al, 2007, Applications of Rough Set Theory to River Environment Quality Evaluation in China. WATER QUALITY AND PROTECTION: ENVIRONMENTAL ASPECTS, Department of Applied Mathematics, The Hong Kong Polytechnic University, Hong Kong

[40] William Ocampo-Duque et al, Assessing water quality in rivers with fuzzy inference systems: A case study, School of Chemical and Process Engineering, Rovira i Virgili University, Avenida de los Países Catalanes 26, 43007 Tarragona, Spain

[41] Yilmaz Icaga (2007), Fuzzy evaluation of water quality classification, Ecological Indicators, 2007, 7(3): 710-718 